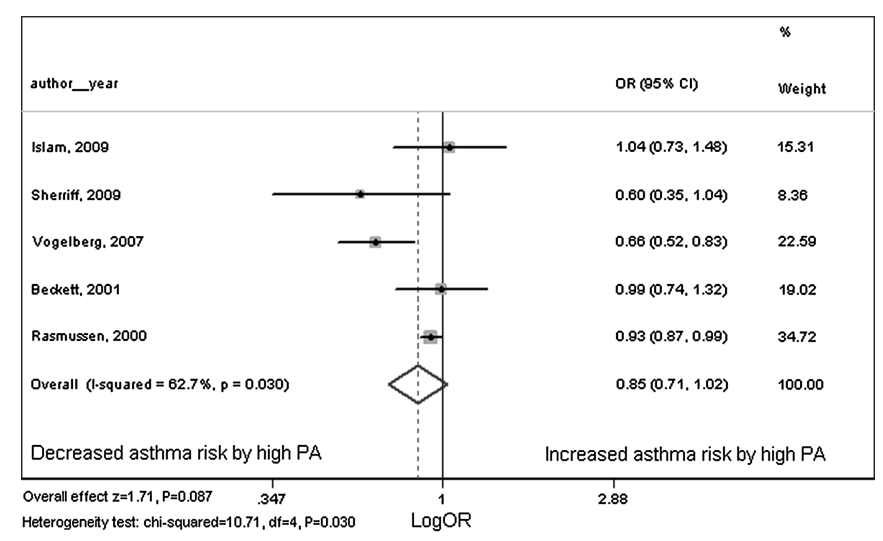

Abstract S84 Figure 1 Random effect meta-analysis of physical activity (PA) and new-onset childhood asthma.

participants $n=12889$; total new-onset asthma $n=912$ ). Metaanalysis of these studies showed the following associations of high PA with new-onset asthma: Random effect model: OR (95\% CI) $0.854(0.713 ; 1.023)$ (Abstract S84 Figure 1$)$ and fixed effect model: 0.909 (0.855; 0.967). I-squared $=62.7 \%$ (both models).

Conclusion The results of this review did support some inverse association between high levels of PA and asthma development in children. However, a limited number of eligible studies were identified and considerable heterogeneity was present.

\section{S85 THE EFFECTS OF EXPOSURE TO IL-9 ALONE OR IN COMBINATION WITH IL-13 ON THE MUCOCILIARY DIFFERENTIATION OF BRONCHIAL EPITHELIAL CELLS FROM NORMAL AND ASTHMATIC CHILDREN.}

doi:10.1136/thx.2010.150938.36

${ }^{1} \mathrm{~J}$ C Parker, ${ }^{1} \mathrm{~S}$ T Thavagnanam, ${ }^{2} \mathrm{G}$ Skibinski, ${ }^{1} \mathrm{M}$ D Shields, ${ }^{1} \mathrm{~L}$ G Heaney. ${ }^{1}$ Centre for Infection and Immunity, Queen's University Belfast, Belfast, UK; ${ }^{2}$ School of Medicine, Dentistry and Biomedical Sciences, Queen's University Belfast, Belfast, UK

Background IL-9 is a pleiotropic Th2 cytokine that has been implicated in the pathogenesis of asthma. IL-9 has been linked to goblet cell hyperplasia and decreased ciliogenesis in animal models and an epithelial injury model in adults. We tested the effects of IL-9 alone and in combination with IL-13, an important cytokine in allergic asthma, during differentiation of bronchial epithelial cells from both asthmatic and normal children.

Hypothesis We hypothesised that bronchial epithelial cells from normal children exposed to IL-9 would result in goblet cell hyperplasia and decreased ciliogenesis, with additional augmented response when treated with a combination of IL-9 and IL-13.

Methods We cultured bronchial epithelial cells from asthmatic and normal children at an air-liquid interface for 28 days. We enumerated the presence of goblet and ciliated cells at the end of the experimental period.

Results IL-9 stimulation alone did not alter goblet cell numbers in differentiating cultures from normal or asthmatic children. IL-9 stimulated PBECs from normal children had reduced ciliated cell numbers and increased MUC5AC secretion at the apical surface which was not seen in asthmatic cells. Combining IL-9 and IL-13 had no additional synergistic effect.

Conclusions We conclude that IL-9 alone or in combination with IL13 did not stimulate goblet cell hyperplasia in bronchial epithelial cells cultures from normal children. We have shown that it is does lower the number of ciliated cells during differentiation of PBECs from normal children however this effect is not seen in cells from asthmatic children.

\section{S86 \\ EFFECTS OF EXPOSURE TO IL-13, IL-31 AND AN IL-13/31 COMBINATION ON MUCOCILIARY DIFFERENTIATION OF BRONCHIAL EPITHELIAL CELLS FROM NORMAL CHILDREN}

doi:10.1136/thx.2010.150938.37

1 J C Parker, ' S T Thavagnanam, ${ }^{2} \mathrm{G}$ Skibinski, 'L G Heaney, ${ }^{1} \mathrm{M} D$ Shields. ${ }^{1}$ Centre for Infection and Immunity, Queen's University Belfast, Belfast, UK; ${ }^{2}$ School of Medicine, Dentistry and Biomedical Sciences, Queen's University Belfast, Belfast, UK

Background Asthma is characterised by airway remodelling which includes smooth muscle hypertrophy, goblet cell hyperplasia and subsequent mucus hyper-secretion. Th2 cytokines including IL-13 and more recently IL-31 have been implicated in the pathogenesis of asthma.

Objectives We aimed to examine the effects of IL-13 $(20 \mathrm{ng} / \mathrm{ml})$, IL$31(20 \mathrm{ng} / \mathrm{ml})$ and an IL-13/31 combination $(20 \mathrm{ng} / \mathrm{ml}$ of both) on the in vitro mucociliary differentiation of paediatric bronchial epithelial cells (PBECs) from normal patients.

Hypothesis We hypothesised that cells from normal children exposed to IL-13, IL-31 or an IL-13/31 combination would alter their phenotype towards that of an asthmatic epithelium.

Methods Markers of differentiation, real time PCR for MUC5AC, MUC5AC ELISA and transepithelial electrical resistance (TEER) were assessed.

Results We found that well-differentiated paediatric bronchial epithelial cells highly expressed the IL-31 receptor (IL-31RA). Transepithelial electrical resistance (TEER) indicated good formation of tight junctions which was found to be similar across all treatment groups. We found that IL-13 stimulation reduced the number of ciliated cells compared with control (IL-13 stimulation: mean $=4.8 \%(\mathrm{SD}=2.5)$; Control: mean $=18.1 \%$, $(\mathrm{SD}=5.9))$. We did not find that the combination of IL-13 and IL-31 had any additional effects to that of IL-13 alone (IL-13/31 combination stimulation: mean $=5.1 \% \quad(\mathrm{SD}=4.6)$; Control: mean $=18.1 \%,(\mathrm{SD}=5.9))$. Stimulation with IL-13, IL-31 and the IL-13/IL-31 combination did not result in any changes of goblet cell numbers.

Conclusions IL-31RA receptor is present in abundance in welldifferentiated paediatric bronchial epithelial cells however IL-31 does not exhibit any detrimental effects on mucociliary differentiation or proliferation. In addition, IL-31 does not appear to have a synergistic effect when combined in culture with IL-13, in the differentiation process.

\section{S87 RELATIONSHIP BETWEEN BRONCHIAL RETICULAR BASEMENT MEMBRANE THICKNESS (RBM) AND SMOOTH MUSCLE MASS IN CHILDHOOD SEVERE ASTHMA (SA)}

doi:10.1136/thx.2010.150938.38

${ }^{1} \mathrm{C}$ J Bossley, ${ }^{1} \mathrm{~N}$ Regamey, ${ }^{1} \mathrm{~L}$ Fleming, ${ }^{2} \mathrm{~T}$ Oates, ${ }^{2} \mathrm{C}$ Lloyd, ${ }^{1} \mathrm{~A}$ Bush, ${ }^{2} \mathrm{~S}$ Saglani. ${ }^{1}$ Royal Brompton Hospital, London, UK; ${ }^{2}$ Imperial College, London, UK

Background In asthma there is a direct relationship between tissue eosinophilic inflammation and RBM thickness. However, relationships between components of remodelling have not been explored, but may be important especially in determining disease severity. There are no reports of an association between smooth muscle mass and asthma severity in children. We hypothesised that increases in both RBM thickness and smooth muscle mass is present in children with SA, only increased RBM thickness is present in mild asthma and neither feature is present in controls.

Methods 75 children, mean age 11.8 (5.6-17.3) years, 53 with SA, 7 with mild/moderate asthma and 15 non-asthmatic controls 